\title{
Above- and below-ground interactions in a leucaena/millet alley cropping system. II. Light interception and dry matter production ${ }^{1}$
}

\author{
J.E. Corlett ${ }^{\mathrm{a}}$, C.R. Black ${ }^{\mathrm{a}}$, C.K. Ong ${ }^{\mathrm{b}, 2}$ and J.L. Monteith ${ }^{\mathrm{b}, 3}$ \\ ${ }^{a}$ Faculty of Agricultural and Food Sciences, Nottingham University, Sutton Bonington, Loughborough \\ LE12 SRD, UK \\ ${ }^{b}$ International Crop Research Institute for the Semi-Arid Tropics (ICRISAT), Patancheru PO, Andhra \\ Pradesh 502 324, India
}

(Received 19 July 1991; accepted 18 February 1992)

\begin{abstract}
Corlett, J.E., Black, C.R., Ong, C.K. and Monteith, J.L., 1992. Above- and below-ground interactions in a leucaena/millet alley cropping system. II. Light interception and dry matter production. Agric. For. Meteorol., 60: 73-91.
\end{abstract}

Leucaena (Leucaena leucocephala (Lam.) de Wit) and pearl millet (Pennisetum glaucum (L.) R.Br.) were grown together in an alley cropping system in a semi-arid area of India. The five treatments included sole millet (SM), sole leucaena (SL) planted in double rows to form hedges with an alley width of $2.8 \mathrm{~m}$, and alley cropping treatments LM5, LM6, and LM6P with alley widths of $2.8,3.3$ and $3.3 \mathrm{~m}$ and five, six and six rows of millet, respectively. LM6P differed from LM6 in that a vertical polythene barrier separated the root systems of leucaena and millet to a depth of $50 \mathrm{~cm}$. Dry matter production and light interception data for millet and leucaena are presented to allow comparison of light capture and utilisation efficiency by the two species under contrasting hedge management in the rainy seasons of 1986 and 1987.

Dry matter yields of leucaena did not differ significantly between treatments in either rainy season, but were much higher in 1987 than in 1986 because of the less severe lopping regime. The higher yields in 1987 resulted from a greater mean fractional light interception by leucaena, which increased shading of alley cropped millet when compared with 1986. The dry matter yields of millet in treatments LM5 and LM6 were reduced relative to the sole crop in both years. In 1986, this reduction appeared to result primarily from shading, while in 1987 the mean fractional light interception and the pre-anthesis conversion coefficient were both lower in LM5 than in SM. Above- and below-ground competition interacted in 1986, so that when root competition was reduced (LM6P) the millet was able to grow taller, eventually matching the leucaena in height and partially escaping the shading and yield reduction experienced in LM5 and LM6.

Correspondence to: J.E. Corlett, Horticulture Research Institute, Wellesbourne, Warwick, CV35 9EF, UK.

${ }^{1}$ ICRISAT Journal Article No. 1261.

${ }^{2}$ Present address: International Council for Research in Agroforestry, P.O. Box 30677, Nairobi, Kenya.

${ }^{3}$ Present address: Institute for Terrestrial Ecology, Bush Estate, Penicuik, EH26 0QB, UK. 
In 1987 , the hedges were always more than $1 \mathrm{~m}$ taller than the millet and the root barrier failed to remove the detrimental competition between leucaena and millet.

\section{INTRODUCTION}

Alley cropping is a form of agroforestry in which food crops are grown.in alleys formed by hedgerows of trees or shrubs. Within their definition of alley cropping, the International Institute of Tropical Agriculture (IITA) state that the hedgerows are normally pruned during cropping to prevent shading and reduce competition with food crops (Kang et al., 1984), implying an important role for light interception in determining yield. Preliminary work in India identified substantial reductions in yield for various annual crops grown between leucaena hedges (Leucaena leucocephala Lam. de Wit), but did not elucidate the nature of the competitive interactions involved (Singh et al., 1989).

Light interception and its conversion to dry matter by individual components have been quantified in several studies of conventional intercropping systems (Marshall and Willey, 1983 for millet and groundnut; Willey et al., 1987 for sorghum and pigeonpea). However, similar studies of alley cropping have so far assessed only the degree of shading imposed on the alley crop by the perennial component, without relating dry matter production to changes in light interception and conversion (e.g. Kang et al., 1985; Singh et al., 1989). Lawson and Kang (1990) measured the radiation incident on maize and cowpea canopies to assess the degree of shading imposed by a range of hedgerow species in an alley cropping system. The trees reduced incident light by $10-80 \%$ depending on hedgerow species and distance from the hedge. However, dry matter production by the annual crops was not highly correlated with incident light levels and no assessment was made of light interception by the maize and cowpea. The present paper aims to quantify light interception and dry matter production by the components of the alley cropping system described earlier (Corlett et al., 1992). A third paper will consider microclimatic modification in the same system.

\section{THEORY}

Dry matter production by any crop or cropping system is often proportional to the quantity of light absorbed by its canopy (Monteith, 1981). This relation holds because the photosynthetic rate of individual leaves tends to respond linearly to increasing irradiance up to the level where they become light saturated. Whole canopy photosynthesis may therefore show a similar response, but with saturation occurring at higher levels of incoming radiation because leaf angle and mutual shading reduce the actual irradiance incident 
- upon individual leaves (Biscoe et al., 1975). The rate of dry matter production is almost proportional to mean photosynthetic rate because respiration is generally a constant percentage of assimilation (Green, 1987).

When water, nutrients and temperature are not limiting, the quantity of dry matter produced by a crop stand $W\left(\mathrm{~g} \mathrm{~m}^{-2}\right)$ can be expressed as

$$
W=\bar{S} \bar{f} \bar{e} t
$$

where $\bar{S}$ is the daily mean solar radiation $\left(\mathrm{MJ} \mathrm{m}^{-2} \mathrm{day}^{-1}\right), \bar{f}$ is the seasonal mean fractional interception of radiation by the canopy, $\bar{e}$ is the seasonal mean conversion coefficient $\left(\mathrm{g} \mathrm{MJ}^{-1}\right)$ and $t$ is the canopy duration in days (Squire et al., 1987). The conversion coefficient, or quantity of dry matter produced per unit of light intercepted, is frequently referred to as 'light use efficiency'. However, the use of 'efficiency' in this context is inappropriate as, technically, this term refers to a dimensionless ratio with a maximum value of unity (Monteith, 1984). During the season, fractional interception $(f)$ is related to leaf area index (LAI) by the equation

$f=1-\exp (-k \mathrm{LAI})$

where $k$ is an extinction coefficient dependent on leaf angle and distribution. With light, as with water and nutrients, biomass production may be increased through greater resource capture (higher $\bar{f}$ and $t$ values) or an increased conversion coefficient (higher $\bar{e}$ ). The same equation can be used when considering the individual components in a cropping system but, although incident radiation will remain unchanged for the cropping system as a whole, the irradiance received by the shorter component may be reduced by shading in systems where one element of the system is significantly taller than the other.

\section{MATERIALS AND METHODS}

Pearl millet (Pennisetum glaucum (L.) R.Br.) and leucaena (Leucaena leucocephala (Lam.) de Wit) were grown in an alley cropping system on a shallow Alfisol at the International Crops Research Institute for the Semi-Arid Tropics (ICRISAT), Patancheru, Hyderabad, India $\left(18^{\circ} \mathrm{N}, 78^{\circ} \mathrm{E}\right.$, altitude $\left.545 \mathrm{~m}\right)$, which experiences three distinct seasons: the rainy season (June-October); the cool, post-rainy season (October-January); the hot summer season (February-May). The experimental design has been described in Corlett et al. (1992) and comprised the following treatments: SM, sole millet cultivar BK 560: $15 \mathrm{~cm}$ spacing within rows and $47 \mathrm{~cm}$ between rows; SL, sole leucaena cultivar K8: two rows $50 \mathrm{~cm}$ apart within hedges, alley width $2.82 \mathrm{~m}$; LM5, alley cropping with five rows of millet spaced as in SM, hedges as in SL; LM6, alley cropping with six rows of millet spaced as in SM, leucaena rows $60 \mathrm{~cm}$ apart within hedges; alley width $3.29 \mathrm{~m}$; LM6P, alley cropping with six rows 
of millet as in LM6 but with a vertical polythene barrier, $50 \mathrm{~cm}$ deep, separating the root systems of millet and leucaena.

Crop management is described fully by Corlett et al. (1992). Rainfall during millet growth was 408 and $334 \mathrm{~mm}$ in 1986 and 1987 , and $87 \mathrm{~mm}$ was received during the post-rainy and summer seasons 1986/1987.

\section{Dry matter production}

\section{Leucaena}

Dry matter production in the form of new shoots was determined at each leucaena harvest. At the initial harvest (10 June 1986) 20 trees were sampled per plot, choosing five adjacent trees from the middle of each of the four central leucaena rows. Thereafter, 28 trees were selected randomly from the two central hedges in each plot, leaving a $2 \mathrm{~m}$ border at each end, and used for all subsequent sampling. At each harvest (see Corlett et al., 1992, table 1) the sample trees were lopped at $65-70 \mathrm{~cm}$ and side branches below this height were also removed. The loppings were separated into green and woody parts. Green material was oven-dried for 2 days at $80^{\circ} \mathrm{C}$, while woody material was dried at the same temperature for at least 1 week. Dry matter production $\left(\mathrm{t} \mathrm{ha}^{-1}\right)$ was calculated from the sample dry weights according to the number of trees in the sample and the number per hectare in each of the treatments. A 'green ratio' ( $G R$ ) was calculated by dividing the dry weight of green material by the total dry weight of the sample.

Dry matter increments in leuceana stems were estimated non-destructively from a regression of dry weight against volume. Stem volume was followed in the sample trees between June 1986 and February 1988. At each sampling date, stem circumference was measured $10 \mathrm{~cm}$ above ground level and $10 \mathrm{~cm}$ below the lopping height. The mean of these two values $(C)$ was used to estimate stem volume by assuming the stem to be a cylinder of circumference $C$. A regression of dry weight $(W, \mathrm{~g})$ against volume $\left(V, \mathrm{~cm}^{3}\right)$ was determined for 50 leucaena stems (range of $V$ from 30 to $145 \mathrm{~cm}^{3}$ ) from marginal areas of the experiment in the post-rainy season of 1986. The regression equation obtained in 1986

$$
W=0.513 V+0.42 \quad\left(r^{2}=0.92\right)
$$

was checked in the summer of 1988 when 48 of the tagged stems were harvested. The regression coefficient and constant were not significantly different $(P>0.05)$ for the larger stems.

\section{Millet}

The growth and development of millet were analysed weekly during the 1986 and 1987 rainy seasons. Sampling began once final thinning had been completed and, at each sequential harvest, samples comprising $1 \mathrm{~m}$ row- 
lengths were taken, leaving at least a $0.5 \mathrm{~m}$ guard area between areas sampled at successive harvests. In the alley cropping treatments, separate samples were taken from all millet rows. The rows were identified according to distance and direction from the hedge; for example, E1 was the first row to the east of the hedge and W3 the third row to the west. In sole millet (SM) single row samples were taken from each replicate plot in 1986 and six rows per plot in 1987. Sample plants were placed in polythene bags and transported to the laboratory for immediate analysis. The plants were then separated into main stems and tillers and then into leaves, stems and panicles. The dry weight of each fraction $(W S)$ was measured after oven-drying at $80^{\circ} \mathrm{C}$ for $48 \mathrm{~h}$ and dry matter per unit land area $\left(W \mathrm{~g} \mathrm{~m}^{-2}\right)$ calculated as:

$$
W=W S / G A
$$

where $G A$ is the ground area occupied by the sample. Both a sequential harvest and a final harvest were taken at the end of each season, with the final harvest material being simply split into grain and fodder. Sampling at final harvest was as described above except that the sample row-length was increased to $6 \mathrm{~m}$ and plant parts were sun-dried for 2 weeks in muslin bags as there was insufficient oven space for the larger samples.

To facilitate comparison of whole system performance, millet dry matter yields were calculated on a 'system area' as well as a 'row area' (or performance) basis. Thus, in eqn. (4) the value for the ground area $(G A)$ occupied by the crop was calculated from the length of the row sample and either the width occupied by millet when dry matter was expressed on a row area basis, or the total pattern width for dry matter expressed on a system area basis. In treatment LM5, the alley width occupied by millet was $2.35 \mathrm{~m}(5 \mathrm{~cm} \times 47 \mathrm{~cm})$ and the pattern width $3.32 \mathrm{~m}$, and so at final harvest, with a $6 \mathrm{~m}$ length of each row being sampled, $G A$ was 14.1 and $19.9 \mathrm{~m}^{2}$ for the row area and system area, respectively.

\section{Hedge shape and millet height}

In 1986, millet height was measured at 44 days after sowing (DAS) and at the last sequential harvest for five plants from one row in SM, five rows in LM5 and three rows (E1, W1, W3) in LM6 and LM6P. In 1987, nine millet plants were tagged in each replicate of treatments SM, LM5 and LM6P in order to follow plant height and phenology. In LM5, three adjacent plants were tagged half-way along Rows E1, C and W1. Sampling in LM6P was similar except that a total of three plants were chosen in Rows E3 and W3 to provide a comparison with Row C in LM5. In SM, three rows were chosen in each plot, and three adjacent plants tagged in each row. The height of the tagged plants was measured at 28,36,50 and 70 DAS, while at 40 and 59 DAS the heights of five plants were measured in each row of each replicate of all 
three alley cropping treatments and in each of six rows of each replicate of SM.

The height of leucaena hedges was not measured directly during 1986 , but was estimated from photographic records. In 1987, measurements of the height and shape of the leucaena hedges were made at 14 day intervals throughout the millet growing season. Hedge height was measured at five randomly selected positions in each plot, while hedge width at a height of $1 \mathrm{~m}$ was measured at the same locations at the first three sampling dates. At later sampling dates, rather than measuring hedge width at a specific height, the height of leucaena branches above ground level was recorded at distances from the base of the hedge corresponding to specific millet row positions.

\section{Light interception}

Tube solarimeters (Green and Deuchar, 1985) were used to measure solar radiation above and below the tree and millet canopies. Positioning of the solarimeters in SM, SL and LM5 has been described (see Corlett et al., 1992; Fig. 1). Millivolt output from the solarimeters was monitored by a Campbell 21X datalogger with three multiplexers (Campbell Scientific, Logan, UT), programmed to scan all channels at 6 min intervals and at the end of each hour to calculate and store the mean of the ten measurements.

\section{RESULTS AND DISCUSSION}

\section{Dry matter production}

Table 1 shows that there were no significant differences between treatments in total above-ground dry matter production or its partitioning between stems and regrowth (loppings) in leucaena during the 1986 rainy season. The stem increment accounted for around $34 \%$ of the total dry matter accumulation in all treatments. Loppings were not routinely separated into green and woody

\section{TABLE 1}

Leucaena dry matter production $\left(\mathrm{tha}^{-1}\right)$. Rainy season 1986. Pooled standard error (SE, $N=3$ ) and variance ratio $(F)$

\begin{tabular}{lcccr}
\hline Treatment & $\begin{array}{l}\text { Stem } \\
\text { increment }\end{array}$ & $\begin{array}{l}\text { Loppings } \\
\text { (23 July) }\end{array}$ & $\begin{array}{l}\text { Loppings } \\
\text { (18 September) }\end{array}$ & Total \\
\hline SL & 1.33 & 0.34 & 2.34 & 4.01 \\
LM5 & 1.30 & 0.37 & 2.30 & 3.97 \\
LM6 & 1.12 & 0.28 & 1.71 & 3.11 \\
LM6P & 1.14 & 0.29 & 1.71 & 3.14 \\
SE & 0.24 & 0.03 & 0.34 & 0.56 \\
$F$ & $<1$ & $<1$ & $<1$ & $<1$ \\
\hline
\end{tabular}


TABLE 2

Leucaena dry matter production ( $\mathrm{t} \mathrm{ha}^{-1}$ ) and green ratios $(G R)$. Rainy season 1987. Pooled standard error $(\mathrm{SE}, N=3)$ and variance ratio $(F)$

\begin{tabular}{llccccc}
\hline Treatment & $\begin{array}{l}\text { Stem } \\
\text { increment }\end{array}$ & $\begin{array}{l}\text { Side cut } \\
\text { (10 August) }\end{array}$ & $\begin{array}{l}\text { Side cut } \\
G R\end{array}$ & $\begin{array}{l}\text { Loppings } \\
\text { (24 September) }\end{array}$ & $\begin{array}{l}\text { Loppings } \\
G R\end{array}$ & Total \\
\hline SL & 1.21 & 1.00 & 0.60 & 4.93 & 0.41 & 7.14 \\
LM5 & 0.97 & 0.94 & 0.60 & 4.50 & 0.42 & 6.41 \\
LM6 & 0.95 & 1.07 & 0.59 & 3.61 & 0.41 & 5.63 \\
LM6P & 0.97 & 1.17 & 0.57 & 4.13 & 0.40 & 6.27 \\
SE & 0.08 & 0.17 & 0.02 & 0.39 & 0.01 & 0.46 \\
$F$ & 2.34 & $<1$ & $<1$ & 2.05 & $<1$ & 1.84 \\
\hline
\end{tabular}

material in 1986 but samples taken from SL and LM5 on 23 July showed a mean green ratio of 0.48 . In 1987 there were again no significant differences between treatments in either total above-ground dry matter production or its partitioning (Table 2). However, the unexplained variability was relatively large, so that the difference of $1.5 \mathrm{tha}^{-1}$ in total dry matter production between treatments SL and LM6 proved non-significant. Green ratios did not differ significantly between treatments for either side branches or loppings, but were higher in the younger side branches sampled on 10 August. Between September 1986 and June 1987, total dry matter production was not signifcantly different in SL and LM5 at $1.5 \mathrm{tha}^{-1}$ and $1.7 \mathrm{tha}^{-1}$, respectively.

In 1986, total above-ground dry matter in millet differed significantly between treatments at all sequential harvests (Fig. 1(a)). SM and LM6P

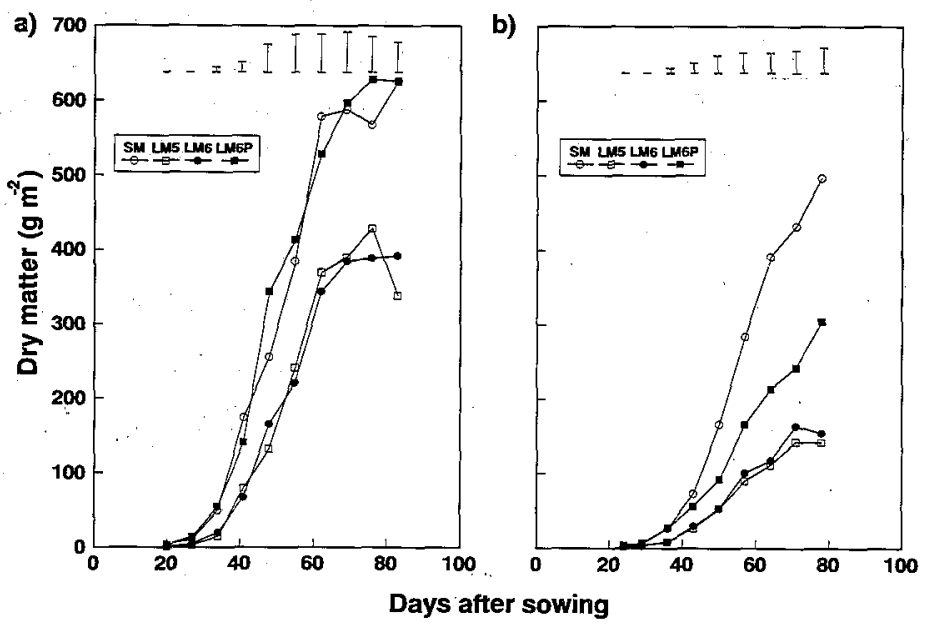

Fig. 1. Above-ground dry matter production by millet in (a) 1986 and (b) 1987 rainy seasons. Bars show double pooled SE. 


\section{TABLE 3}

Total above-ground dry matter production $\left(\mathrm{tha}^{-1}\right)$, seasonal mean fractional light interception $(f)$, total light interception $\left(\bar{S} f t, \mathrm{MJ} \mathrm{m}^{-2}\right)$ and seasonal mean conversion coefficient $\left(\bar{e}, \mathrm{~g} \mathrm{MJ}^{-1}\right)$. Pooled standard error (SE, $N=3$ )

\begin{tabular}{|c|c|c|c|c|c|c|c|}
\hline \multirow[t]{2}{*}{ Year } & \multirow[t]{2}{*}{ Season } & \multirow[t]{2}{*}{ Treatment } & \multicolumn{2}{|c|}{ Dry matter } & \multirow[t]{2}{*}{$f$} & \multirow[t]{2}{*}{$\overline{S f} t$} & \multirow[t]{2}{*}{$\vec{e}$} \\
\hline & & & Millet & Leucaena & & & \\
\hline \multirow[t]{4}{*}{1986} & \multirow[t]{4}{*}{ Rainy } & SM & 4.7 & - & 0.43 & 581 & 0.81 \\
\hline & & SL & - & 4.0 & 0.38 & 519 & 0.77 \\
\hline & & LM5 & 3.1 & 4.0 & 0.60 & 809 & 0.88 \\
\hline & & SE & 0.7 & 0.6 & - & - & - \\
\hline \multirow[t]{3}{*}{$1986 / 1987$} & \multirow[t]{3}{*}{ Post-rainy/summer } & SL & - & 1.5 & 0.25 & 1270 & 0.12 \\
\hline & & LM5 & - & 1.7 & 0.23 & 1160 & 0.15 \\
\hline & & SE & - & 0.5 & - & - & - \\
\hline \multirow[t]{4}{*}{1987} & \multirow{4}{*}{ Rainy } & SM & 5.0 & - & 0.40 & 504 & 0.98 \\
\hline & & SL & - & 7.1 & 0.48 & 861 & 0.82 \\
\hline & & LM5 & 0.9 & 6.4 & 0.52 & 928 & 0.79 \\
\hline & & $\mathrm{SE}$ & 0.4 & 0.5 & - & $47^{\circ}$ & - \\
\hline
\end{tabular}

initially accumulated dry matter more rapidly than LM5 and LM6, but all treatments showed little further increase after 62DAS. By the end of the season LM5 and LM6 had accumulated $42 \%$ less dry matter than the other two treatments. This difference was attributable to differences in both main stem and tiller dry matter production. In 1987, above-ground dry matter production was much slower in all three alley cropping treatments than in sole millet and there were significant differences at nearly all sequential harvests (Fig. 1(b)). The treatment differences were mainly because the tillers were both lighter and fewer in number in the alley cropping treatments (Corlett, 1989).

Total dry matter yields at final harvest, expressed on a system area basis, for both millet and leucaena are shown in Table 3. The yield of leucaena depends on many factors, including age, climatic conditions, spacing and cutting regime. The yields of 4 and $7.1 \mathrm{tha}^{-1}$ for SL in the 1986 and 1987 rainy seasons (each of 3 months) compare favourably with the value of $1.8 \mathrm{tha}^{-1}$ month $^{-1}$ reported for cultivar $\mathrm{K} 8$ in the more humid climate of Hawaii (Guevarra et al., 1978). The total yield during the 9 month post-rainy/ summer season of 1986/1987 was much lower than in either rainy season, reflecting the low rainfall and high saturation deficits experienced during this period. Sole millet yields were much lower in both years than the value of $8.1 \mathrm{tha}^{-1}$ reported by Marshall and Willey (1983) for the same variety and soil at ICRISAT. Their crop was also rainfed but received more than twice the rainfall recorded during the 1986 and 1987 rainy seasons. The combined dry 
TABLE 4

Millet height $(\mathrm{cm})$ at various days after sowing (DAS). Pooled standard error $(\mathrm{SE} ; N=3)$

\begin{tabular}{|c|c|c|c|c|c|c|c|c|}
\hline \multirow[t]{2}{*}{ Year } & \multirow[t]{2}{*}{ DAS } & \multirow[t]{2}{*}{ Row } & \multicolumn{4}{|c|}{ Treatment } & \multirow[t]{2}{*}{$\mathrm{SE}$} & \multirow[t]{2}{*}{$P$} \\
\hline & & & SM & LM5 & LM6 & LM6P & & \\
\hline \multirow[t]{2}{*}{1986} & 44 & Mean & 94 & 69 & 63 & 115 & 3 & $<0.001$ \\
\hline & 83 & Mean & 143 & 146 & 139 & 160 & 3 & $<0.05$ \\
\hline \multirow[t]{2}{*}{1987} & 40 & Mean & 28 & 28 & 39 & 69 & 3 & $<0.01$ \\
\hline & 59 & Mean & 125 & 126 & 135 & 147. & 6 & ns \\
\hline \multirow[t]{4}{*}{1987} & 40 & E1 & 27 & 22 & 27 & 54 & 4 & $<0.01$ \\
\hline & 40 & W1 & 26 & 22 & 27 & 52 & 3 & $<0.01$ \\
\hline & 59 & $\mathrm{E} 1$ & 128 & 85 & 77 & 93 & 9 & $<0.05$ \\
\hline & 59 & W1 & 131 & 102 & 106 & 125 & 6 & $<0.05$ \\
\hline
\end{tabular}

ns, not significant.

matter production of leucaena and millet in LM5 was greater than for either sole stand during both rainy seasons, although significantly so only in 1986 .

\section{Heights of millet and leucaena}

In 1986, millet was significantly taller in treatment LM6P than in the other three treatments at both 44 and 83 DAS (Table 4 ), whereas sole millet was taller than that in LM5 and LM6 only at 44 DAS. Row-to-row differences within the treatments were very small (data not shown). In 1987, the treatment means differed significantly at $40 \mathrm{DAS}$ but not at 59DAS, although the ranking of treatments was similar at both sampling dates (LM6P > LM6 > $\mathrm{SM}=\mathrm{LM} 5$ ). The sole crop grew more rapidly than the millet rows adjacent to the hedges and by 59 DAS was taller than Rows E1 and W1 in all three alley cropping treatments. At 59DAS there was a distinct trend across the alleys, with millet height being proportional to distance from the hedge (data not shown). There was also some asymmetry, with millet in rows to the west of the hedge being taller than in corresponding rows to the east (Table 4).

There were no significant differences between treatments in the height of leucaena at any of the sampling dates in 1987. The mean height of leucaena during the millet growing season is compared with that of millet in SM and the central row of each alley cropping treatment in Fig. 2. The leucaena was invariably at least $1.5 \mathrm{~m}$ taller than the central millet row in all treatments. Measurements of hedge shape indicated that hedge width $1 \mathrm{~m}$ above the ground was $1.8 \mathrm{~m}$ at $31 \mathrm{DAS}$, but that the hedges were not symmetrical. The prevailing westerly winds bent the regrowth shoots so that by $67 \mathrm{DAS}$ 


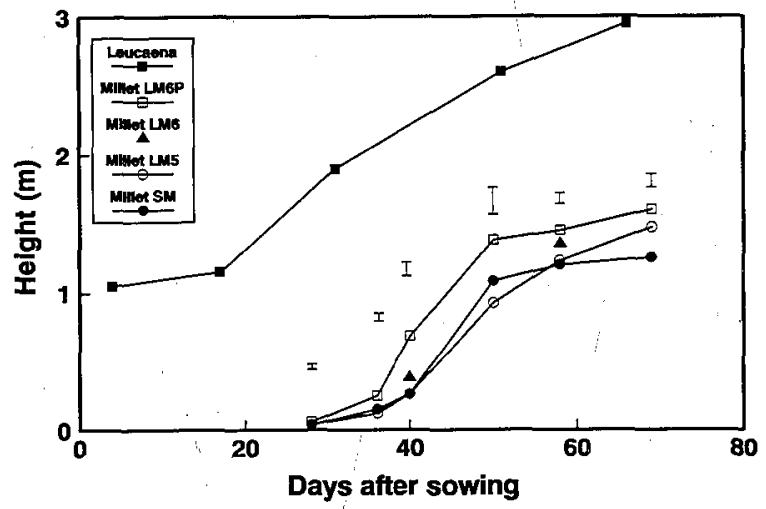

Fig. 2. Relative heights of leucaena (mean of all treatments) and millet in 1987 rainy season. Bars show double pooled SE for millet.

leucaena branches overhung Rows E1, E2 and W1, but not W2, in all three alley cropping treatments.

\section{Light interception}

Five-day means for fractional light interception $(f)$ in treatments SM, SL and LM5 are shown in Fig. 3. In 1986, the leucaena hedges were lopped (at a height of $70 \mathrm{~cm}$ ) 2 weeks before sowing the millet and again at $29 \mathrm{DAS}$, as is reflected by the decrease in $f$ between 25 and 30 DAS in both SL and LM5 (Fig. 3(a)). Values of $f$ were lowest in treatment SL because the hedges were too far apart and lopped too frequently for the canopy to close, and so much incoming radiation fell on bare soil in the centre of the alleys. Fractional interception by LM5 represents the combined interception by leucaena and millet and was consistently higher than in either SM or SL. The partitioning of light interception between millet and leucaena is considered below.

In $1987, f$ was already 0.25 in SL and LM 5 by 5 DAS while that in SM was still near zero (Fig. 3(b)). Removal of the leucaena side branches at 43 DAS slightly decreased $f$ values in both LM5 and SL. Interception was consistently higher in LM5 than in SL, although the 5-day means were never significantly different. Sole millet intercepted very little radiation before the start of rapid canopy expansion at $30 \mathrm{DAS}$. Leaf senescence in both sole and alley cropped millet was largely responsible for the decrease in $f$ between 65 and $80 \mathrm{DAS}$, although decreased interception by the leucaena also contributed, as also occurred in SL, as the prevailing hot, dry weather promoted leaf folding by leucaena.

Measurements of light interception in LM5 and SL continued until midNovember (data not shown), when the solarimeters were removed for recalibration, and recommenced at the beginning of February 1987. During this 

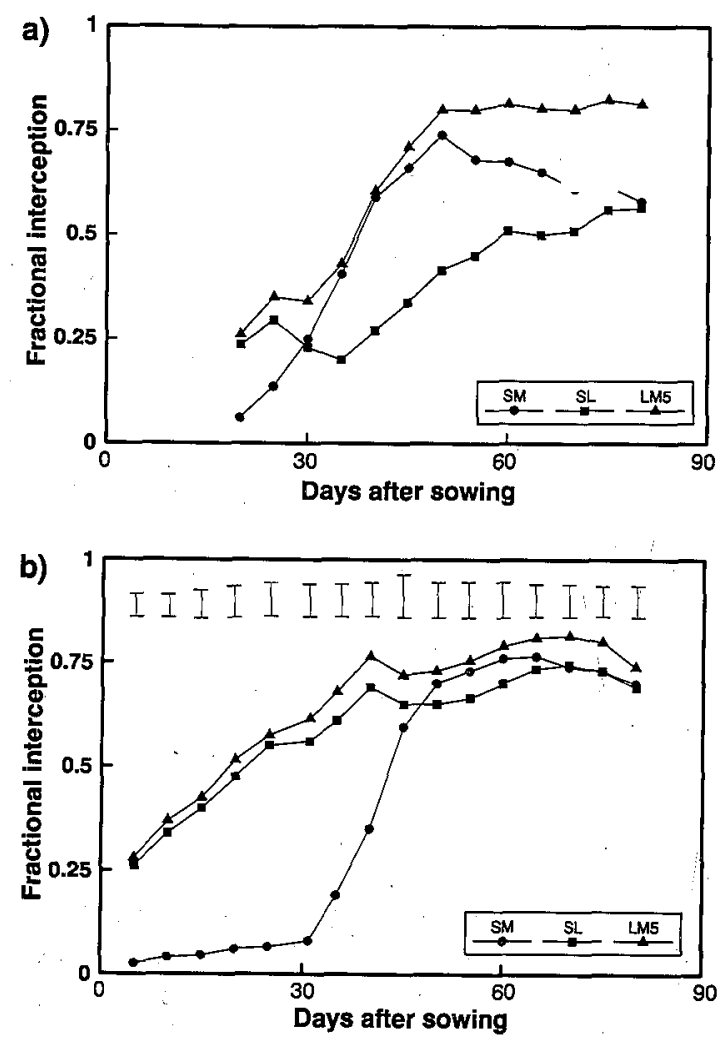

Fig. 3. Five-day means for total fractional light interception in (a) 1986 and (b) 1987 rainy seasons. Bars show double pooled SE.

period, $f$ values rose from 0.2 just after lopping to $0.3-0.4$ in early February. During the summer season, fractional interception decreased steadily to only 0.1 in early May because of wilting and leaf-fall.

\section{Partitioning of light interception in LMS}

In 1986, light interception could not be partitioned between millet and leucaena because the solarimeters were positioned so as to measure interception by the combined canopy. However, an indirect estimate may be made if it is assumed that: (1) the hedges in LM5 were identical in shape, leaf area and extinction coefficient to those in SL; (2) measurements from each of the five solarimeters in the alleys of LM5 represented light interception by a single millet row, together with any interception by leucaena. Light interception by specific millet rows in $\operatorname{LM5}\left(y, \mathrm{MJ} \mathrm{m}^{-2}\right)$ may then be calculated on a daily basis as

$y=S\left(f_{\mathrm{LM}}-f_{\mathrm{L}}\right)$ 
where $S$ is the incident solar radiation on that day, $f_{\mathrm{LM}}$ is $1-f_{\mathrm{tLM}}$ and $f_{\mathrm{L}}$ is $1-f_{\mathrm{tL}}$, where $f_{\mathrm{tLM}}$ and $f_{\mathrm{tL}}$ are fractional transmitted solar radiation measured by the solarimeters under that millet row and in the corresponding position in SL, respectively. Assumption 1 may be justified on the grounds that the trees in all treatments were of the same cultivar, were managed in the same way, experienced similar environmental conditions and produced the same amount of dry matter during the rainy season (Table 1). Thus, if the conversion coefficient was conservative for leucaena, it follows that the hedges in LM5 and SL would have intercepted similar quantities of light. Field observations suggested that the hedges were very similar in shape and form, while growth analysis revealed no differences between SL and LM5 in dry matter partitioning between stem increment and regrowth. Assumption 2 is valid when solar elevation is high and the canopies of individual millet rows are discrete. When solar elevation is low and the canopies intermingle, the errors introduced will be important only when adjacent millet rows differ significantly in LAI. The estimates of light interception by individuals rows in LM5 are therefore most reliable for the central three rows and least reliable for EI and W1. Daily values of interception calculated from eqn. (5) and accumulated over the growing season for Rows E1, E2, C, W2 and W1 were $296 \mathrm{MJ} \mathrm{m}^{-2}$, $400 \mathrm{MJ} \mathrm{m}^{-2}, 447 \mathrm{MJ} \mathrm{m}^{-2}, 403 \mathrm{MJ} \mathrm{m}^{-2}$ and $278 \mathrm{MJ} \mathrm{m}^{-2}$ respectively, indicating that total interception by millet was greatly reduced in Rows E1 and W1.

Direct partitioning of light interception was possible in 1987 because of the different placement of the solarimeters, but it was not possible to calculate row-by-row interception as solarimeters spanned several millet rows. Light interception by millet on specific days may be calculated from eqn. (5) if $f_{\mathrm{tL}}$ and $f_{\mathrm{tLM}}$ are redefined as fractional transmission measured by the solarimeters above and below the millet canopy in LM5. Multiplication by 0.71 converts the light interception values from a row area to a system area basis. Total light interception by millet in LM5 was $180 \pm 18 \mathrm{MJ} \mathrm{m}^{-2}$, significantly lower than the value of $504 \pm 47 \mathrm{MJ} \mathrm{m}^{-2}$ for $\mathrm{SM}$. Light interception was not uniform across the alley, with total interception by millet to the east and west of the hedge being $159 \pm 23 \mathrm{MJ} \mathrm{m}^{-2}$ and $202 \pm 14 \mathrm{MJ} \mathrm{m}^{-2}$, respectively. Although this difference was not significant, the millet on the west of the hedges intercepted $>12 \%$ more light than that to the east in all three replicates.

\section{Conversion of light energy to dry matter}

The seasonal mean conversion coefficients ( $\bar{e}$, in eqn. (1)) shown in Table 3 were calculated using values for total intercepted radiation and the corresponding above-ground dry matter production (system area basis). Light interception outside the measurement period was estimated by linear extrapolation of $f$. The $\bar{e}$ values for SM were lower in both years than previously reported values (e.g. $1.6 \mathrm{~g} \mathrm{MJ}^{-1}$; Overseas Development Administration, 
1987), but consistent with recent field measurements at ICRISAT of 0.89$1.29 \mathrm{~g} \mathrm{MJ}^{-1}$ (Ong et al., 1991). Values were similar in SL and SM, which is surprising since $\mathrm{C}_{4}$ crops such as millet have inherently higher conversion coefficients than $C_{3}$ crops such as leucaena (Foyer, 1984). The leucaena was, however, already established at the beginning of the rainy season, with a well developed root system, whereas the millet may have had to invest a higher proportion of its dry matter production in root growth, material which was not included in the calculation of $\bar{e}$. The leucaena also suffered less dry matter loss through senescence than millet.

The mean conversion coefficient for leucaena during the post-rainy and summer seasons was approximately $20 \%$ of that in the rainy season (Table 3 ). Stomatal closure may have been the main cause of this reduction as the trees received only $87 \mathrm{~mm}$ of rainfall during this 9 month period. Loss of dry matter through leaf-fall may also have contributed, although no assessment of this was made.

The seasonal mean conversion coefficients for millet mask major variations in $e$ during the growing season, as is demonstrated by the relations between accumulated light interception and dry matter yield for millet in SM and LM5 (Fig. 4). Comparison of the coefficients for the linear regressions indicates that the $e$ values for millet in SM (Fig. 4(a)) and LM5 (Fig. 4(b)) decreased after anthesis in both years. Coefficients for SM and LM5 did not differ significantly either before or after 62 DAS in 1986, whereas in 1987 the pre-anthesis conversion coefficient in LM5 was significantly reduced $(P<0.05)$ relative to SM. Using the equation of Marshall and Willey (1983) to calculate the interception of photosynthetically active radiation (PAR) by leucaena, it was estimated that more than half of the apparent reduction in the pre-anthesis conversion coefficient was attributable to the reduced quality of light reaching the millet in LM5 (Corlett, 1989).

\section{Assessment of factors limiting total treatment yields}

The differing dry matter production between treatments may be explained in terms of the interception and conversion of light energy to dry matter (eqn. (1)). This type of analysis has been used previously to explain yield advantages in intercropping (Marshall and Willey, 1983; Willey et al., 1987) but has apparently not been applied to any agroforestry systems.

Total dry matter yield during the rainy season of 1986 (Table 3) was $50-80 \%$ higher in LM5 than in SM or SL because of greater resource capture $(\bar{f})$ in the former treatment. $\bar{S}$ and $t$ were similar in all treatments and differences in $\bar{e}$ were small relative to the variability in $\bar{f}$ and $W . \bar{f}$ was lower in SL than in LM5 because the widely spaced hedges could not utilise light in the centre of the alley, and was low in SM because of incomplete ground cover during early growth. In the 1987 rainy season, treatments SL and LM5 
a)

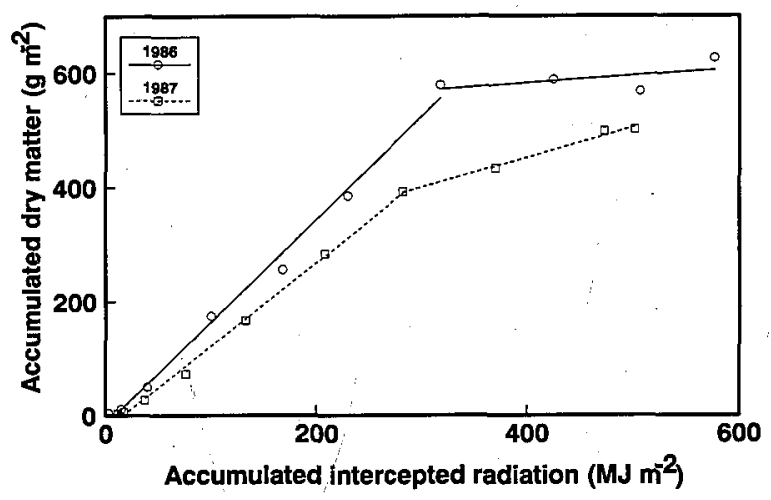

b)

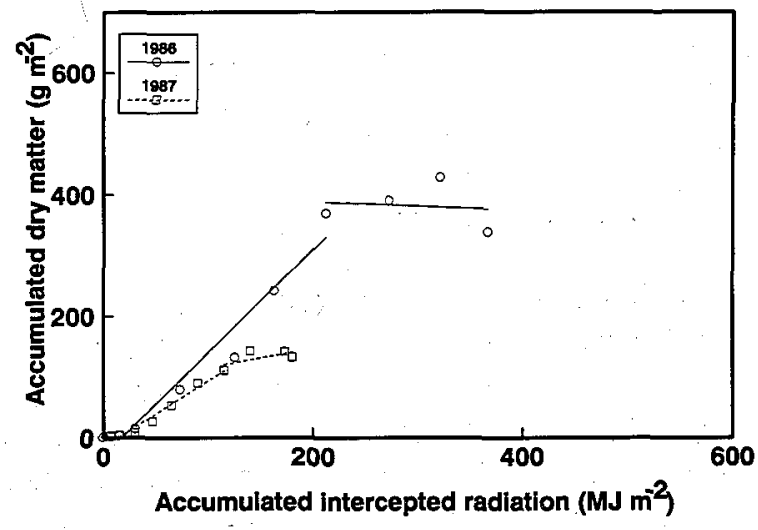

Fig. 4. Relation between accumulated above-ground dry matter and intercepted radiation for (a) sole millet and (b) alley cropped millet in LM5. Coefficients for regression lines fitted to pre- and post-anthesis values are, respectively, $1.80\left(r^{2}=0.99\right)$ and $0.13\left(r^{2}<0.50\right)$ for SM in 1986, 1.46 $\left(r^{2}=0.99\right)$ and $0.53\left(r^{2}=0.99\right)$ for SM in $1987,1.72\left(r^{2}=0.96\right)$ and $-0.04\left(r^{2}<0.50\right)$ for LM5 in 1986 and $1.09\left(r^{2}=0.96\right)$ and $0.33\left(r^{2}<0.50\right)$ for LM5 in 1987.

produced more dry matter than SM because a higher mean fractional interception was maintained for longer. However, the greater light interception in treatments containing leucaena was partly off-set by the lower seasonal mean conversion coefficients. The $\bar{f}$ values for both SL and LM5 could conceivably have been increased by altering hedge management or spacing, thereby increasing $W$. The greater dry matter production by LM5 than either sole stand appears to have originated from the capture of more light $(\bar{S} \bar{f} t)$, rather than improved light use efficiency. Natarajan and Willey (1980) have previously reported that a sorghum/pigeonpea intercrop intercepted more light than either sole crop because the differing rates of canopy development 
TABLE 5

Components of millet yield, rainy season 1986, expressed as a percentage of the corresponding values for $\mathrm{SM}$

\begin{tabular}{|c|c|c|c|c|c|c|c|c|c|}
\hline \multirow[t]{2}{*}{ Treatment } & \multirow[t]{2}{*}{ Variable } & \multicolumn{7}{|c|}{ Row } & \multirow[t]{2}{*}{ Mean } \\
\hline & & El & E2 & E3 & $\mathrm{C}$ & W3 & W2 & W1 & \\
\hline \multirow[t]{4}{*}{ LM5 } & $W$ & 32 & 63 & - & 58 & - & 75 & 42 & 54 \\
\hline & $\bar{S}$ & 61 & 81 & - & 86 & - & 82 & 65 & 76 \\
\hline & $\bar{f}$ & 84 & 86 & - & 88 & - & 82 & 74 & 83 \\
\hline & $\bar{e}$ & 63 & 91 & - & 76 & - & 108 & 88 & 85 \\
\hline LM6 & $W$ & 47 & 74 & $71^{\circ}$ & - & 69 & 76 & 38 & 63 \\
\hline LM6P & $W$ & 80 & 88 & 88 & - & 125 & 98 & 121 & 100 \\
\hline
\end{tabular}

$W$, total dry matter production; $\bar{S}$, total incident light; $\bar{f}$, seasonal mean fractional light interception; $\bar{e}$, seasonal mean conversion coefficient.

and crop duration led to temporal separation of the periods of maximum light interception (thereby increasing $\bar{S} \bar{f} t$ ). However, they were not able to separate resource use by the individual components.

\section{Factors limiting yield of individual components}

Table 5 shows row-by-row values for light interception and utilisation by millet in LM5 in 1986, expressed as a percentage of the corresponding values in SM. The $\bar{S}, \bar{f}$ and $\bar{e}$ values for millet were all reduced by alley cropping, although it appears that $\bar{S}$ was the most important factor in reducing the dry matter yields in all rows except E1, which experienced reductions in both $\bar{S}$ and $\bar{e}$ of almost $40 \%$.

The $8 \%$ reduction in leucaena yield in LM5 relative to SL in 1987 reflected reductions in $\bar{f}$ and $\bar{e}$ of $6 \%$ and $2 \%$, respectively (Table 6 .). However, as leucaena yields did not differ significantly between these treatments, it is unlikely that the apparent reductions in $\bar{f}$ and $\bar{e}$ represent any real change in leucaena performance. Reductions in $\bar{S}, \bar{f}$ and $\bar{e}$ all contributed to the greatly reduced millet yield in LM5 relative to the sole crop. The value of $\vec{f}$ was most affected by alley cropping and, on a system area basis, the $59 \%$ reduction takes account of both the effects of lower LAI per row and the fact that millet occupied only $71 \%$ of the equivalent land area in LM5. The lower $\bar{e}$ value in alley cropped millet may be largely attributable to the altered spectral quality of the incident light after preferential absorption of PAR by the leucaena canopy. Shading by leucaena reduced $\bar{S}$ for millet to a greater extent to the east than to the west of the hedges (Table 6). The analysis shows that, on a performance area basis, the reductions in millet yield of $77 \%$ and $69 \%$ relative to SM were equally attributable to reductions in $\bar{S}$ and $\bar{f}$, with changes in $\bar{e}$ being less important. 


\section{TABLE 6}

The variables for rainy season 1987, for leucaena and millet in LM5 expressed as a percentage of that in the corresponding sole crop (system area), and for millet on the east and west side of the hedge in LM5 expressed as a percentage of that in SM (performance area)

\begin{tabular}{lccccc}
\hline Species & \multicolumn{2}{l}{ Variable } & & & \\
\cline { 2 - 5 } & $\bar{S}$ & $\bar{f}$ & $\bar{e}$ & $t$ & $W$ \\
\hline Millet & 59 & 41 & 76 & 100 & 18 \\
Leucaena & 100 & 94 & 98 & 100 & 92 \\
Millet & & & & & \\
East of hedge & 54 & 58 & 73 & 100 & 23 \\
West of hedge & 64 & 63 & 78 & 100 & 31 \\
\hline
\end{tabular}

$\bar{S}$, total incident light; $\bar{f}$, seasonal mean fractional light interception; $\bar{e}$, seasonal mean conversion coefficient; $t$, crop duration; $W$, total dry matter production.

Marshall and Willey (1983) assessed light capture and utilisation by individual components of a millet/groundnut intercrop in order to elucidate the yield advantage of intercropping over sole cropping. In contrast to our results, the performance of both crops was improved by intercropping, an effect attributed to increases in $\bar{e}$ in groundnut and $\bar{f}$ in millet. Reported intercropping advantages in the semi-arid tropics have generally been for systems such as that described by Marshall and Willey, where a tall $\mathrm{C}_{4}$ crop shades a shorter $\mathrm{C}_{3}$ species. As the photosynthesis of tropical $\mathrm{C}_{3}$ crops may be lightsaturated in full sunlight, shading by a taller component may lead to reduced light interception without any effect on dry matter production. In alley cropping systems, the taller component is usually a $\mathrm{C}_{3}$ species and if a $\mathrm{C}_{4}$ cereal is grown in the alley, shading will inevitably lead to reduced assimilation, compared with a sole crop, unless photosynthesis is already limited by stomatal closure (McPherson and Slatyer, 1973).

\section{Above- or below-ground competition?}

If $\bar{S}$ and $\bar{f}$ were the main determinants of millet yield in LM5 in 1986, this would also be expected to apply to LM6 and LM6P. LM5 and LM6 both showed quadratic trends in $W$ across the alleys, while LM6P showed no such trend (Corlett, 1989). The row-by-row values for LM6 and LM6P (Table 5) indicate that, whereas mean dry matter production in LM6 was only $63 \%$ of that in SM, yields in LM6P and SM were identical. This implies that millet yields in LM 5 and LM6 were limited only by below-ground interactions. If the $\bar{f}$ values for millet are assumed to be identical in SM and LM6P (based on their very similar yields) and $\bar{S}$ for LM6P is calculated from the values for LM5 (assuming individual $\bar{S}$ values for Rows $\mathrm{E} 3$ and $\mathrm{W} 3$ were equal to that for LM5 Row C), it appears that $\bar{e}$ must have been $30 \%$ higher in LM6P than in 
SM. Such a large change in $\bar{e}$ is difficult to explain and an alternative hypothesis is that $\bar{e}$ was similar in SM and LM6P, but that millet in the latter treatment escaped some of the shading experienced in LM5 and LM6 by virtue of its greater height (Table 4).

In 1987, the leucaena hedges were always more than $1 \mathrm{~m}$ taller than the millet and total millet dry matter yields on a performance area basis were $294 \mathrm{~g} \mathrm{~m}^{-1}$ and $248 \mathrm{~g} \mathrm{~m}^{-2}$ lower, respectively, in LM6 and LM6P than in SM (Fig. 1). Thus, assuming that there was no below-ground competition in LM6P and that above-ground interactions were entirely responsible for the observed yield reduction, it may be postulated that a similar yield reduction of $248 \mathrm{~g} \mathrm{~m}^{-2}$ may be attributed to above-ground competition in LM6, with below-ground effects accounting for the remaining decrease of $46 \mathrm{~g} \mathrm{~m}^{-2}$. However, the effects of above- and below-ground competition are not generally additive and if, for example, the shading effects of leucaena in LM6 were removed without altering the below-ground demands of the hedge, the increased light incidence on millet in the alley would probably lead to a greater LAI and higher leaf temperatures, so increasing the demand for water by the millet and the below-ground competition with leucaena. In the present experiment, the reduced light levels in LM6 may have reduced the water requirements of millet to a level which more closely matched the lower water availability.

Singh et al. (1989) used a root barrier to separate above- and below-ground interactions in a leucaena-based alley cropping system with $10 \mathrm{~m}$ wide alleys and hedges pruned to $1 \mathrm{~m}$ (except for one tree every $2 \mathrm{~m}$ which was allowed to grow for pole production). The barrier removed most of the competition between leucaena and sorghum, and Singh et al. (1989) concluded that yield reductions in sorghum adjacent to the hedge were mainly the consequence of competition for water even though shading of $85 \%$ was recorded in rows adjacent to the hedge. It appears that above- and below-ground effects were again not additive as the root barrier not only removed root competition, but also caused height and girth increments of leucaena to be reduced by $35 \%$. It may be assumed therefore that canopy size and shading by the hedges were also reduced, although this was not recorded. In contrast to these results from alley cropping, the presence of root barriers in a millet/groundnut intercrop had no significant influence on component yields and the intercrop outperformed the sole crops as a result of increased $\bar{f}$ and $\bar{e}$ values (Willey and Reddy, 1981; Marshall and Willey, 1983).

\section{CONCLUSIONS}

The differing hedge management adopted in the two rainy seasons was the principal factor determining light interception and dry matter yields of leucaena in both sole and alley cropping treatments, and consequently also 
controlled millet productivity in LM5 and LM6 (Table 3). The dry matter yield of leucaena in LM5 was $2.4 \mathrm{tha}^{-1}$ higher in 1987 than 1986, mainly because $\bar{f}$ was increased, but this was only achieved at the expense of a $2.2 \mathrm{tha}^{-1}$ reduction in millet yield.

The results presented here suggest that both above- and below-ground competition reduced the yields of alley-cropped millet relative to the sole crop. In 1986, although shading appeared to be a major factor in reducing millet yield in LM5 (Table 5), the root barrier was able to remove all deleterious competition at the tree/crop interface, thus underlining the interactive nature of above- and below-ground effects. It is clear that manipulation of hedge spacing and lopping regime in this type of alley cropping will be a most powerful tool for regulating the relative and absolute yields of the two components during the rainy season.

\section{ACKNOWLEDGEMENTS}

J.E. Corlett wás supported by the Isle of Man Board of Education and research facilities were provided by the International Crops Research Institute for the Semi-Arid Tropics. The authors acknowledge the assistance of members of ICRISAT Resource Management Program for field work and data analysis. We particularly thank A.A.H. Khan, D. Midya and B. Uday Kumar.

\section{REFERENCES}

Biscoe, P.V., Scott, R.K. and Monteith, J.L., 1975. Barley and its environment. III. Carbon budget of the stand. J. Appl. Ecol., 12: 269-293.

Corlett, J.E., 1989. Leucaena/millet alley cropping in India: microclimate and productivity. $\mathrm{PhD}$ thesis, University of Nottingham, UK.

Corlett, J.E., Ong, C.K., Black, C.R. and Monteith, J.L., 1992. Above- and below-ground interactions in a leucaena/millet alley cropping system. I. Experimental design, instrumentation and diurnal trends. Agric. For. Meteorol., 60: 53-72.

Foyer, C.H., 1984. Photosynthesis. Wiley, New York, 219 pp.

Green, C.F., 1987. Nitrogen nutrition and wheat growth in relation to absorbed solar radiation. Agric. For. Meteorol., 41: 207-248.

Green, C.F. and Deuchar, C.N., 1985. On improved solarimeter construction. J. Exp. Bot., 36: 690-693.

Guevarra, A.B., Whitney, A.S. and Thompson, J.R., 1978. Influence of intra-row spacing and cutting regimes on growth and yield of leucaena. Agron. J., 70: 1033-1037.

Kang, B.T., Wilson, G.F. and Lawson, T.L., 1984. Alley Cropping. A Stable Alternative to Shifting Cultivation. International Institute for Tropical Agriculture, Ibadan, Nigeria, $23 \mathrm{pp}$.

Kang, B.T., Grimme, H. and Lawson, T.L., 1985. Alley cropping sequentially cropped maize and cowpea with leucaena on sandy soil in Southern Nigeria. Plant Soil, 85: 267-277.

Lawson, T.L. and Kang, B.T., 1990. Yield of maize and cowpea in an alley cropping treatment in relation to available light. Agric. For. Meteorol., 52: 347-357.

McPherson, H.G. and Slatyer, R.O., 1973. Mechanisms regulating photosynthesis in Penniseturn typhoides. Aust. J. Biol. Sci., 26: 329-339. 
Marshall, B. and Willey, R.W., 1983. Radiation interception and growth in an intercrop of pearl millet/groundnut. Field Crops Res., 7: 141-160.

Monteith, J.L., 1981. Does light limit crop production? In: C.B. Johnson (Editor), Physiological Processes Limiting Plant Productivity. Butterworths, London, pp. 23-28.

Monteith, J.L., 1984. Consistency and convenience in the choice of units for agricultural science. Exp. Agric., 20: 105-117.

Natarajan, M. and Willey, R.W., 1980. Sorghum-pigeonpea intercropping and the effects of plant population density. II. Resource use. J. Agric. Sci., 95: 59-65.

Ong, C.K., Subrahmanyam, P. and Khan, A.A.H., 1991. The microclimate and productivity of a groundnut/millet intercrop during the rainy season. Agric. For. Meteorol., 56: 49-66.

Overseas Development Administration. 1987. Microclimatology in tropical agriculture; Vol. 1. Final Report, Research Schemes R3208 and R3819. ODA, London, 202 pp.

Singh, R.P., van den Beldt, R.J., Hocking, D. and Korwar, G.R., 1989. Alley cropping in the semi-arid regions of India. In: Proc. of Alley Cropping Workshop, 10-14 March 1989, International Institute for Tropical Agriculture, Nigeria, IITA, Nigeria, pp. 108-122.

Squire, G.R., Ong, C.K. and Monteith, J.L., 1987. Crop growth in semi-arid environments. In: Proc. of Int. Pearl Millet Workshop, 7-11 April 1986, ICRISAT Center, Patancheru. ICRISAT, India, pp. 219-231.

Willey, R.W. and Reddy, M.S., 1981. A field technique for separating above- and below-ground interactions in intercropping: an experiment with pearl millet/groundnut. Exp. Agric., 17: 257264.

Willey, R.W., Reddy, M.S. and Natarajan, M., 1987. Conventional cropping systems for Alfisols and some implications for agroforestry systems. In: Alfisols in the Semi-Arid. Tropics. Proc. of Consultant's Workshop, 1-3 December 1983, ICRISAT Center, India. ICRISAT, Patancheru, India, pp. 155-163. 